\title{
IMPACT OF STIGMA AND DISCRIMINATION ON SEXUAL WELLBEING OF LGBTI STUDENTS IN A SOUTH AFRICAN RURAL UNIVERSITY
}

\author{
A. H. Mavhandu-Mudzusi \\ Department of Health Studies \\ University of South Africa \\ Pretoria, South Africa \\ e-mail:mmudza@unisa.ac.za
}

\section{ABSTRACT}

Lesbian, gay, bisexual, transgender and intersex (LGBTI) students in South African institutions of Higher Education face stigma and discrimination. This is happening despite the country's constitution that prohibits any form of discrimination of an individual based on sexual orientation or gender identity. The study objective was to explore and describe the impact of stigma and discrimination on sexual-wellbeing of LGBTI students in a South African rural university. An interpretative phenomenological analysis design was used to conduct a study. Individual semistructured interviews were conducted with 20 LGBTI students. Results indicate that LGBTI students try to avert stigma and discrimination through hiding their true sexual orientation and gender identity. In the process, they end up engaging in sexual practices which increase the risk of contracting or transmitting sexual transmitted infections including HIV. The researcher recommends that the university should initiate programmes for ensuring social justice for LGBTI affirmation.

Keywords: discrimination, homophobia, LGBTI students, sexual-wellbeing, South African rural university, stigma.

\section{BACKGROUND}

Lesbian, gay, bisexual, transgender and intersex (LGBTI) individuals are found in almost every country. Studies show that in the United States of America, approximately 2.3 million women describe themselves as lesbians (Marrazzo 2004). Estimating the number of LGBTI persons in Africa is a difficult task to achieve, as many members of this population are not open about their sexual orientation because of fear of persecution. People who engage in same-sex relationship or non-gender conforming are criminalised as well as considered as taboo in most African countries (Goddard 2004; Mudavanhu 2010). Globally, Africa has some of the worst laws on same-sex relationships (Carroll and Itaborahy 2015). Taking Zimbabwe as an example, homosexuality is openly condemned by senior politicians and religious leaders, and people with such sexual orientation often suffer violence and aggression (Mabvurira et al. 2012; Smith 2015). 
Though in other African countries being a non-heterosexual individual and gender nonconforming is considered a taboo, few countries, such as Kenya and South Africa, have constitutions that protect individuals from exposure to stigma and discrimination based on sex (Ellis 2008; Human Rights Watch 2011). Stigma refers to a strong feeling of disapproval that most people in society have about something (in this case is being non-heterosexual and being gender non-conforming) whereas discrimination is a practice of treating a particular group in a society less fairly than others (Hornby 2010). While South Africa's Constitution of 1996 was the first in the world to include provisions for non-discrimination against people based on sexual orientation, LGBTI individuals in South Africa continue to face hostility and violence. Such reactions towards this population indicate a disparity or gap between the ideals of the Constitution, which calls for non-discrimination and equality for all people who live in South Africa (Human Rights Watch 2011; Reading and Rubin 2011).

A huge concern is that stigma and discrimination towards LGBTI individuals do not only occur in the community but also in the institutions of higher education. This happens despite a legal obligation for the universities to protect minority groups on campus (Ellis 2008). One of the minority groups is LGBTI population. Despite this legal obligation, several studies report that LGBTI students are still exposed to stigma and discrimination. A study conducted by Arndt and De Bruin (2006) in Gauteng, South Africa, indicated that heterosexual students expressed hate and hostility towards LGBTI students. Mavhandu-Mudzusi and Netshandama (2013) documented that while there are some students who accommodate LGBTI students, the majority of students have negative attitudes towards this population group. It was interesting to find that in both groups of students (those who have negative attitudes and those with positive attitudes towards LGBTI students) religion was considered the main reason for those attitudes. Similar findings were recorded by Mavhandu-Mudzusi and Sandy (2015), reporting that stigma and discrimination experienced by LGBTI students at a South African-rural university is mainly based on religious beliefs of university community. Mavhandu-Mudzusi and Ganga-Limando (2014) further mentioned that, apart from religious beliefs, culture and gender play major roles in stigma and discrimination experienced by LGBTI individuals. The stigma and discrimination experienced by LGBTI students in a South African rural based university, is experienced almost everywhere on campus including lecture halls, student residential areas and sports grounds (Mavhandu-Mudzusi 2014). The presence of stigma and discrimination in such vast areas mean that stigma and discrimination are institutionalised as described by Hardiman and Jackson (1997) cited in Francis and Francis (2006).

Institutionalised stigma and discrimination might lead to some LGBTI individuals trying 
several means to hide their true gender identity or sexual orientation by engaging in the behaviours that create the impression that they are 'straight' (Lane et al. 2008; MavhanduMudzusi 2014; Mavhandu-Mudzusi and Sandy 2015). This made the researcher to wonder how the LGBTI students meet their sexual wellbeing while still trying to avert stigma and discrimination. It led the researcher to conduct this study which explored the impact of stigma and discrimination on the sexual-wellbeing of LGBTI students in a South African rural university. In this study, sexual-wellbeing means being in control of one's own sexual decision, sexual practices and sexual consequences including access to means of mitigating the risk related to sexual activities.

\section{METHOD}

\section{Design}

Interpretative Phenomenological Analysis (IPA) design was used to gain understanding of the impact of stigma and discrimination the sexual-wellbeing of LGBTI students in a South African rural university. IPA allows the researcher not only to explore the meanings but also interpret those meanings through participant-researcher interactions (Smith 2005). Interpretative Phenomenological Analysis design requires researchers to seek to understand participants' experiences and the meanings they attribute to them within a specific socio-cultural context (Smith 2005; Langdridge 2007).

\section{Study setting}

The study was conducted in a South African rural university in the Limpopo Province. The institution, which was established during the apartheid era, currently caters largely for students from a wide range of local rural communities. The majority of the university community members adhere to the cultural practices and beliefs of those rural communities. One of the beliefs is that being gender non-conforming or non-heterosexual is a taboo or a result of being bewitched (Mavhandu-Mudzusi and Netshandama 2013; Mavhandu-Mudzusi 2014).

\section{Sampling and sample size}

Snowballing technique was utilised for recruiting participants. Sampling commenced when a female bisexual student, who reported having sex with and being attracted to both women and men, visited the HIV unit for HIV counselling and testing. The researcher, who was working in the HIV/AIDS unit during the study period, recruited the student to participate in the study. 
This was done after providing information regarding the study such as aim, purpose, significance, participant's rights and voluntary participation. After the provision of informed consent by the student, a request was made to the student to refer other students who met the eligibility criteria for participation. These included: being an LGBTI student who have been at the South African rural university for at least two years. Being at the university for two years ensures that the student has already adjusted to the university environment. A total of 20 students consisted of the following self-identified categories: five lesbians, three bisexual females, three transgender (female-to-male), two transgender (male-to-female), two bisexual males, and five gays participated in the study. Sample size was determined by category saturation. The age of students sampled ranged between 19 and 25 years.

\section{Data collection}

The researcher collected data between June and October 2012 through individual semistructured interviews. The interviews were guided by an interview guide designed in keeping with IPA principles (Smith 2005). All interviews began from the following statement: 'Kindly share with me the impact of stigma and discrimination towards LGBTI students on your sexual wellbeing' The research used communication skills such as minimal encouragers, probes, prompts, and paraphrasing to elicit more detailed information from participants. Each interview was audio-recorded and lasted for about 45 to 60 minutes. Field notes were also taken to capture and describe non-verbal cues observed during interviews.

\section{Ethical considerations}

Ethical clearance to conduct the study was obtained from the South African rural university's Research and Ethics Committee. The researcher thoroughly explained the purpose of the research and its potential benefit, which include the potential for advocacy and support of the LGBTI population group on campus. The possible impact for participating in the study was also explained. To reduce the risk of exacerbating stigma and discrimination towards participants, all interviews were conducted in the HIV/AIDS Unit to ensure strict confidentiality. The use of names was avoided at all cost, where it was unavoidable, pseudonyms were used. During the transcription of the data, the researcher omitted using descriptors which could also make the participant identifiable, such as the name of the sporting code, the faculty where the student came from and the name of the institution. Participants were given written information, which included their freedom to withdraw. The issue of participation being voluntary was stressed. The participants were requested to use pseudonyms when signing 
consent forms in order to protect their identity. A psychologist was made available to counsel the participants who appeared to be depressed after the interview. All participants were debriefed after interview and those who needed further interventions were referred to relevant sources.

\section{Measures to ensure trustworthiness}

Guba and Lincoln`s (1994) framework of trustworthiness was adopted in this study, as it fits in well with the IPA design which focuses on the co-creation of meanings through participantresearcher interactions. It includes five criteria; credibility, dependability, confirmability, transferability and authenticity (Polit and Beck 2012). Dependability and confirmability were ensured through the audio recording of interviews and field notes. Furthermore, samples of the audio recorded data were transcribed and analysed by an independent coder, who is an expert in qualitative research and gender and sexual issues. The researcher and the independent coder agreed on the outcome of their analysis. Member checking and validity checks were done to enhance the credibility and dependability of the study outcomes. To ensure credibility transcripts were sent to some participants to determine their accuracy and in all cases participants were satisfied. Validity checks on the master list of themes were carried out by an independent researcher to ensure that the themes were relevant and evidenced in the data.

\section{Data analysis}

All audio-recorded interviews were transcribed verbatim in written text. The 20 transcripts were analysed independently by the researcher using Smith's (2005) IPA data analysis framework. Analysis was conducted iteratively with data collection until category saturation was achieved. The researcher read each transcript several times to familiarise with the data and made notes in the process. Emergent themes were identified and related themes were clustered in superordinate categories. A master table of themes for each transcript was developed containing superordinate theme, sub-themes and associated quotations. All the master tables of themes were then compared for similarities and differences. This process led to the development of a single master table composed of a superordinate theme, sub-themes and associated excerpts from transcripts.

\section{RESULTS}

Results indicate that LGBTI students engage in diverse sexual practices to be 'seen as straight' in order to avert stigma and discrimination. Some of practices compromise their sexual- 
wellbeing. This was well demonstrated by the superordinate theme that emerged from data analysis namely: Engagement in HIV risky sexual practices.

\section{Engagement in HIV risky sexual practices}

This superordinate theme refers to the sexual behaviours which LGBTI students are engaged in to be seen complying to 'normal sexual orientation and gender identity' in order to avert stigma and discrimination. Some of the sexual practices that emerged from data analysis are: sharing sexual partners, multiple concurrent partners and seizing sexual opportunity.

\section{Sharing sexual partners}

Fear of stigmatisation and discrimination makes a lot of LGBTI students in a South African rural university to completely hide their sexual and/or gender identity. Not disclosing sexual orientation or gender identity make it difficult to identify people who are members of LGBTI population group. This lead to the situation LGBTI students sometimes share sexual partners between LGBTI support group members. The reason provided for such behaviour is scarcity of people who are openly living as LGBTI individuals at this rural university.

Most of homosexuals are living in a closet due to the fear of stigma and discrimination. This make it very difficult to get a sexual partner at this university. We end up dating among support group members, and even cheating with each other's partner.

Because people will tell you that you are a sinner or possessed by demons, even if you see a person whom you feel sexually attracted to, you cannot propose love due to fear of being ridiculed, stigmatised or even physically assaulted. You end up targeting only the LGBTI who are known, and those are the once we meet during the support group meetings. Most of them already have their partners. So if one is infected with HIV, it become very easy to infect the rest of the group members.

Apart from sharing sexual partners among the LGBTI support group members, some of the LGBTI students publicly engage in relationships with heterosexual individuals.

\section{Multiple concurrent sexual relationships}

This theme relates to the practice of having more than one sexual partner simultaneously. Participants mentioned that LGBTI students are 'forced' to engage in heterosexual relationships publicly while privately having a partner of their choice based on their sexual orientation. This practice is done to mask the true sexual orientation in order to avert stigma and discrimination.

Before I came to this university, I was living openly as a lesbian. When I arrived at the university, one of my classmates showed me a lesbian couple and mentioned that I should not go near them because they are 'bitch'. When I started dating girls, people gossiped about me saying that I am a 
'bitch, satanic and demon possessed'. Others mentioned that I am afraid of 'dick'. These derogatory names forced me, and even other LGBTI students in this university to publicly engage in heterosexual relationships to prove that we are 'normal' while privately continuing with our homosexual relationships.

Sometimes, instead of dating heterosexual individuals to prove being 'straight', which may at the end create a huge problem if they (LGBTI) individuals are found that they are pretending, some LGBTI individuals end up having multiple sexual practices among the circle of LGBTI population groups. Participants consider this sort of multiple concurrent behaviour as being innovative.

We (LGBTI community) are now sorted. Instead of encroaching into the world of heterosexual individuals, we create heterosexual couples among ourselves. A feminine gay can date a 'butch' (Masculine) female. What we call 'Gaybian'. This solves all our problems and those unnecessary issues of stigma and discrimination. For those feminine gays who use to have problems of being abused by the masculine men, they are engaged in relationships among each other, that is transgender male to female only dating each other, this relationship is termed 'gaysbian'. However, we continue to have lovers/partners of our choice. And as we are all in the same situation of averting stigma and discrimination, we understand each other. When the university community see these types of relationships, they become confused about our gender identity and sexual orientation as they assume that we are straight. They end up leaving us alone.

Another sexual behaviour which LGBTI individuals are engaged in is seizing sexual opportunities.

\section{Seizing sexual opportunities}

Fear of stigma and discrimination contribute to some LGBTI students engaging in sex at any place any time whenever they assume that it is convenient, when they meet a sexual partner whom they are attracted. This is due to fear of missing the 'sexual-opportunity'. This sexual practice is called 'quickie or microwave sex' by participant as it is done very fast in any place including toilets in fear of being discovered and labelled as 'LGBTI individual'

Most of our sexual encounters are done in un-conducive areas such as bar toilets as that are the places where we can meet the partner. We usually ensure that we quickly have sex before people notice that we have disappeared from the gathering and that is what we call 'quickie' or 'microwave sex'.

These types of sexual encounters which are mainly unplanned include engaging in unprotected sex which led others to be infected with HIV as indicated by the following excerpt from one of the interview transcript:

This is the way I got infected, I got someone at the airport, we rushed to the toilet and had sex, we did not have a condom and the partner was in a hurry to get a flight and we did not want to 'miss 
the sexual opportunity'. You know what happens when you are hungry for something. When you see food, which you know will soon disappear; you cannot wait because you will starve. That is what happened to me because the university and community denied us freedom to engage in sex freely with partners of our choice. When I went for HIV test after two months, I was told that I am HIV positive.

\section{DISCUSSION}

The outcome of this study reveals that stigma and discrimination negatively affect the sexual wellbeing of students in a South African rural university. Due to fear of stigma and discrimination, LGBTI students in a South African rural based university try all means to convince the university community that they are straight individuals. Some of the means of proving 'straightness' is confining the search for a sexual partner only among the LGBTI individuals who are members of LGBTI support group because of fear of approaching anybody outside the circle, who may end up disclosing their sexual behaviour to the rest of university community. The disclosing of one sexual orientation to the university community where stigma and discrimination against LGBTI is institutionalised according to Mavhandu-Mudzusi (2014), may lead to severe negative consequences. However, this engagement to sexual activities by LGBTI student among only members of support group, where sometimes there is intersexions (intermixing of sexual partners) as they even share sexual partners. The intersexions may end up leading to the spread of sexually transmitted infections including HIV to the entire group.

Another equally risky sexual behaviour which LGBTI students are engaged in is that of having more than one sexual partner at a time. One sexual partner will be the heterosexual partner in order to be seen by the university community as straight person in order to avert stigma and discrimination. While they are publicly seen with the heterosexual partner, they continue to privately continue to have sexual relationship with partners of their choice. This practice 'forced' multiple concurrent sexual relationships also predispose LGBTI individuals to ether contract or spread sexually transmitted infections including HIV.

Though this practice may assist the LGBTI individuals to temporarily avert stigma and discrimination, some LGBTI individuals mention that there is a possibility of this situation to backfire if a heterosexual individual/partner realise that the relationship was fake. This end up bringing more stigma and discrimination and even gender based violence. In order to avoid such situation, some LGBTI student start to have sexual relationships with people of different sex among the LGBTI circle. For an example, a gay man will date a lesbian women so that the community will assume that they are heterosexual couple. However, as this is just a 'public relationship', they still continue to have relationships with the partners of their choice. The only reason for having a 'so called heterosexual encounter' with the members of LGBTI group is 
just that all the partners understand that it is just a public relationship to avert stigma and discrimination. Similar findings were reported by Ellis (2008), mentioning that bisexuality is commonly seen as a 'safe' alternative to a lesbian or gay identity. Though the practice seems safer in relation to the violence which may occur when the 'real partner' find out about the relationship, engaging in multiple concurrent sexual relationships, still pose the high risk of contracting or spreading HIV.

The difficulties of openly having sexual encounters with partner of choice, make some LGBTI individuals to try by all means to use whatever opportunity to have sexual relationship with partner of their choice wherever they have a slight opportunity. However, as the sexual encounter is usually not pre-planned, the chance of utilising protective materials such as condoms are limited, which further increase the risk of contracting sexual transmitted infection. The fact that this is also done fast at the places such as the toilets in the bars, the possibility is that the individuals may be under the influence of alcohol which may hinder their capacity of putting on the condoms even if it may be available. These findings attest to literature mentioning that stigma related to being a member of a sexual minority fuel the spread of HIV as it obscures open discussion about sexuality and seeking proper preventative measures (Jobson et al. 2012; Muraguri, Temmerman and Geibel 2012).

All these practices negatively affect the sexual wellbeing of LGBTI individuals as they cannot freely engage in sexual relationship with partners of their choice. They also have little control or choice on the place where they are supposed to have sexual encounter as they are always afraid of being discovered and face stigma and discrimination from the university community. The situation also affects the planning of their sexual encounter as most of the time they just try to seize any moment which they feel slightly save regardless of the conduciveness of the environment. These emergency encounter hinder them from using proper precautionary measures such as pre-exposure prophylaxis and condoms to prevent them from contracting or spreading HIV. Even after unprotected sexual encounter, it may not be easy for the LGBTI individual to access the post exposure prophylaxis from the health care services as there is institutionalised stigma and discrimination in a South African rural university in case (Mavhandu-Mudzusi and Sandy 2015).

\section{CONCLUSION AND RECOMMENDATIONS}

Because of the stigma and discrimination experienced by LGBTI students, they engage in different sexual practices to try and create the impression that they are straight. The sexual behaviours include sharing sexual partners, concurrent multiple partners and unprotected sexual 
intercourse while trying to seize the sexual opportunities. Some of those behaviours increase their risk of contracting or spreading HIV among the LGBTI individuals and also to some heterosexual individuals.

As universities are supposed to be agents of transformation, and centres which should ensure equal access to all qualifying students without discrimination, the university should initiate programmes such as diversity management, gender and sexual diversity awareness campaigns and infusion of gender and sexual diversity in compulsory university modules such as English Communication Skills. The university should also institute serious disciplinary actions against the university members who stigmatise and discriminate against LGBTI students. There should also be a workshop on health-related aspects and the citizenship rights of LGBTI individuals. The training will empower the LGBTI students to advocate for their own rights. As the university is a microcosm of society at large, and reflects the homophobia of the society, there should also be awareness campaigns aimed at the community to assist them in respecting the citizenship rights of LGBTI individuals.

\section{REFERENCES}

Arndt, M. and G. P. de Bruin. 2006. Attitudes toward lesbians and gay men: Relations with gender, race and religion among university students. Psychology in Society 33: 16-30.

Carroll, A. and L. P. Itaborahy. 2015 International Lesbian, Gay, Bisexual, Trans and Intersex Association: State sponsored homophobia 2015: A world survey of laws: criminalisation, protection and recognition of same-sex love. Geneva: ILGA.

Ellis, S. J. 2008. Diversity and inclusivity at university: A survey of the experiences of lesbian, gay, bisexual and transgender (LGBT) students in the UK. Higher Education 57: 723-739.

Francis, D. and E. Francis. 2006. Raising awareness of HIV related stigma and its associated prejudice and discrimination. South African Journal of Higher Education 20(1): 48-59.

Goddard, K. 2004. Fair representation. GALZ and the history of gay movement in Zimbabwe. Journal of Gay and Lesbian Social Services 16(1): 75-98.

Guba, E. G. and Y. S. Lincoln. 1994. Competing paradigm in qualitative research. In Handbook of qualitative research, ed. K. D. Denzil and Y. S. Lincoln, 105-117. Thousand Oaks, CA: Sage Publications.

Hardiman, R. and B. W. Jackson. 1997. Conceptual foundations for social justice courses. In Teaching for diversity and social justice: A sourcebook, ed. M. Adams, L. A. Bell and P. Griffin, 16-29. New York: Routledge.

Hornby, A. S. 2010. Oxford Advanced Learner's Dictionary. United Kingdom: Oxford University Press.

Human Rights Watch. 2011. 'We'll show you you're a woman'. Violence and discrimination against black lesbians and transgender men in South Africa. United States of America: Human Rights Watch.

Jobson, G. A., L. B. Theron, J. K. Kaggwa and H. Kim. 2012. Transgender in Africa: Invisible, inaccessible, or ignored? Journal of Social Aspects of HIV/AIDS 9(3): 160-163.

Lane, T., T. Mogale, H. Struthers, J. McIntyre and S. M. Kegeles. 2008. 'They see you as a different thing': The experiences of men who have sex with men with healthcare workers in South African 
township communities. Sexually Transmitted Infections 84: 430-433.

Langridge, D. 2007. Phenomenological psychology: Theory, research and methods. London: Pearson.

Mabvurira, V., P. D. Motsi, T. Masuka and E. E. Chigondo. 2012. The 'politics' of sexual identities in Zimbwabwe: A social work perspective. International Journal of Humanities and Social Sciences 2(13): 218-223.

Marrazzo, J. M. 2004. Barriers to infectious disease care among lesbians. International Conference on Women and Infectious Diseases (ICWID) 10(11) 1974-1978. USA: University of Washington.

Mavhandu-Mudzusi, A. H. 2014. Experiences of lesbian, gay, bisexual, transgender and intersex students regarding sports participation in a South African rural based university. African Journal for Physical, Health Education, Recreation and Dance 20(2:2): 710-720.

Mavhandu-Mudzusi, A. H. and R. M. Ganga-Limando. 2014. Being lesbian, gay, bisexual, transgender and intersex (LGBTI) students in a South African university: Implications for HIV prevention. African Journal of Nursing and Midwifery 16(2): 125-138.

Mavhandu-Mudzusi, A. H. and V. O. Netshandama. 2013. The attitudes of students towards the lesbian, gay, bisexual, transgender and intersex community: A case of a South African rural-based university. The African Journal for Physical, Health Education, Recreation and Dance Supplement 1(1): 56-66.

Mavhandu-Mudzusi, A. H. and P. T. Sandy. 2015. Religion-related stigma and discrimination experienced by lesbian, gay, bisexual and transgender students at a South African rural-based university. Culture, Health \& Sexuality: An International Journal for Research, Intervention and Care. DOI: 10.1080/13691058.2015.1015614.

Muraguri, N., M. Temmerman and S. Geibel. 2012. A decade of research involving men who have sex with men in sub-Saharan Africa: Current knowledge and future directions. Journal of Aspects of HIV/AIDS 9(3): 137-147.

Mudavanhu, J. 2010. The attitudes of the Methodist Church in Zimbabwe to homosexuality, towards a socio-sexological theological investigation. PhD thesis. College of Arts and Law: The University of Birmingham.

Polit, F. D. and C. T. Beck. 2012. Nursing research-generating and assessing evidence for nursing practice. $9^{\text {th }}$ Edition. London: Lippincott Williams \& Wilkins.

Reading, R. and L. R. Rubin. 2011. Advocacy and empowerment: Group therapy for LGBT asylum seekers. Traumatology 17(2): 86-98.

Smith, J. A. 2005. Reflecting on the development of interpretative phenomenological analysis and its contribution to qualitative research in psychology. In Qualitative Research in Psychology 1: 3954.

Smith, L. 2015. Human Rights Day: Transgender men suffer violence and hate crimes too. http://www.ibtimes.co.uk/human-rights-day-transgender-men-suffer-violence-hate-crimes-too1532586 (accessed 25 August 2016). 